Research Article

\title{
A survey study based on undergraduate medical students' feedback regarding pathology and the teaching-learning methodologies employed
}

\author{
Vijayan $\mathbf{P}^{1}$, Ponniah $\mathbf{A}^{2}$ \\ ${ }^{1}$ Dr. Poornima Vijayan, Assistant Professor, ${ }^{2}$ Dr. Anupama Ponniah, Associate Professor, both authors are affiliated with \\ Department of Pathology, MES Medical College, Kerala, India.
}

Address for Communication: Dr. Poornima Vijayan, Assistant Professor, Dept of Pathology, MES Medical College, Perinthalmanna, Kerala, India. Email: poornima2785@gmail.com

\begin{abstract}
Background: It cannot be emphasized enough that a solid understanding of pathology is the foundation for a good clinical practice. And, Pathology, being a vast subject with the number of lecture hours being limited, understanding the students' perspective is essential for generating interest in the subject and for gaining essential knowledge and skills during those limited hours assigned. Aim: This study was aimed at understanding the students' perspective regarding pathology as a subject and about the effectiveness of the various teaching-learning methods currently used by the faculty of our department. Materials \& Methods: This study was carried out on $812^{\text {nd }}$ MBBS students (regular batch) who have completed 3 semesters of pathology using a predesigned questionnaire with questions pertaining to students' perception of pathology and the various teaching learning methods currently used by the faculty. Results: A vast majority of the students, $96.6 \%$, found pathology to be an interesting subject. About $95 \%$ of them agreed that a sound knowledge of pathology was useful during their clinical postings and for their clinical practice. Majority of the students, $76.6 \%$, were satisfied with content of the lectures taken. $93.3 \%$ of them felt that enough stress has been laid on important topics during the lecture classes and important points have been highlighted adequately. Popular modes of teaching learning were casebased discussions and group discussion (96.6\%), Powerpoint presentations (88\%), black board teaching (78.3\%), integrated teaching (83.3\%). 96.65\% of the students agreed that written exams were a very effective assessment tool. Among the changes suggested by the students, the point most mentioned was that more practical exams and monthly tests need to be conducted because pathology was perceived as a vast subject. Lack of effective teacher-student communication was also mentioned in $6 \%$ of the feedback forms. Conclusion: Our study showed that most students had a positive attitude towards pathology as a subject as well as the various teaching learning methods employed by the faculty of our department. Most students felt case based discussions and integrated teaching to be among the most effective ways of gaining knowledge.
\end{abstract}

Keywords: Students' perception of pathology, Feedback, Teaching learning methods

\section{Introduction}

Second MBBS is a crucial period in undergraduate education because this is when the student is initiated into clinical postings and taught the etiology and pathogenesis of various disease processes [1]. Pathology bridges the gap between basic sciences and clinical medicine and this subject is important because a proper understanding of pathological processes is vitally important for medical practice [2].

Manuscript received: $15^{\text {th }}$ April 2017

Reviewed: 26 ${ }^{\text {th }}$ April 2017

Author Corrected: $4^{\text {th }}$ May 2017

Accepted for Publication: $11^{\text {th }}$ May 2017
The main goals of undergraduate pathology teaching have always been to provide a framework for the description of disease and to provide students with knowledge of the functional and structural changes in disease so that clinical signs and symptoms can be understood and interpreted [2]. With pathology teaching hours having decreased over the years, this is a difficult aim which requires fine planning [3]. The balancing of teaching hours with the available faculty and student motivation is a major difficulty. For a successful general improvement of the curricula student 
Research Article

involvement in the process is essential. In teaching, students' wishes regarding the curriculum are of utmost importance, especially in a field like pathology where teaching must be trimmed to assist students in effectively retaining extensive amounts of knowledge [4].

And in order to understand the students' perspective and to assess the effectiveness of teaching/learning method used, here, we have used feedback from the students for this study. We hope that this study will help in improving the quality of teaching and contribute to overall faculty development in our institution as well as other upcoming institutions.

\section{Aim}

This study was aimed at understanding the students' perspective regarding pathology as a subject and about the effectiveness of the various teaching-learning methods currently used by the faculty of our department.

\section{Materials and Methods}

\section{Study design: Cross sectional study}

Setting: This study was carried in MES medical college, Kerala. The participants were $812^{\text {nd }}$ MBBS students (regular batch) who have completed 3 semesters of pathology.
Inclusion and exclusion criteria: $2^{\text {nd }}$ year $M B B S$ students who have completed 3 semesters in Pathology teaching and were going to appear for their university exams having more than $75 \%$ attendance. Repeaters and supplementary batch students were excluded from this study. Students with less than $75 \%$ attendance were also excluded from the study.

Sample size: $812^{\text {nd }}$ year MBBS students

Data souce: Data was collected at the end of 3 semesters of pathology using a predesigned questionnaire.

Questionnaire:A predesigned, structured, pre-validated questionnaire after peer review, was used to gather information regarding students' perception of pathology and about the various teaching learning methods currently used by the faculty.

The questionnaire included 17 questions and space was also provided for any suggestions or changes recommended.

Statistical analysis of the data: Data entry and analysis was done using Microsoft Excel/Epi Info. Percentages were used to analyze the data.

Consent: Informed verbal consent was taken from them prior to collection of data.

\section{Results}

A Total of 81 students (regular batch) who were going to appear for the $2^{\text {nd }}$ MBBS university exams participated in our study. All of them returned the completed questionnaire. Of the $81,86.4 \%$ were female students and $13.6 \%$ were male students.

A vast majority of the students, $96.6 \%$, found pathology to be an interesting subject. $95 \%$ of them agreed that a sound knowledge of pathology was useful during their clinical postings and for their clinical practice in future. 93.3\% were of opinion that an integrated mode of teaching pathology along with other clinical specialty subjects will help in better understanding of various diseases. $65 \%$ of the students found systemic pathology to be more difficult than general pathology, while $28.3 \%$ of the students felt general pathology was easier than systemic pathology (Table 1)

Majority of the students, $76.6 \%$, were satisfied with content of the lectures taken and only $15 \%$ felt otherwise. $85 \%$ felt that the number of lectures taken on each topic was adequate, while only $8.3 \%$ felt this was inadequate.

$81.6 \%$ felt that a duration of 1 hour per lecture was adequate. $93.3 \%$ of them felt that enough stress has been laid on important topics during the lecture classes and important points have been highlighted adequately.

$78.3 \%$ of the students were satisfied with the explanations given while clarifying doubts asked during the lectures. $68.3 \%$ said that they were satisfied with the style of delivery and pace of the lectures, while $25 \%$ said they were not. $76.6 \%$ said that they were encouraged to ask and answer questions during the lectures and practical classes. (Table 2) 
Table-1: Students' perception about pathology as a subject.

\begin{tabular}{|c|c|c|c|c|}
\hline S.No & Questions & Yes (\%) & No (\%) & $\begin{array}{c}\text { Don't } \\
\text { Know }\end{array}$ \\
\hline 1. & Do you find pathology interesting? & $96.6 \%$ & $3.4 \%$ & $0 \%$ \\
\hline 2. & Does a sound knowledge of pathology help in clinical posting? & $95 \%$ & $0 \%$ & $5 \%$ \\
\hline 3. & $\begin{array}{c}\text { Does integration of pathology teaching with clinical subjects help } \\
\text { in better understanding of disease concepts? }\end{array}$ & $95 \%$ & $0 \%$ & $5 \%$ \\
\hline 4. & Is general pathology more difficult than systemic pathology? & $28.3 \%$ & $65 \%$ & $6.7 \%$ \\
\hline
\end{tabular}

Table-2: Teaching methodology: content and quality.

\begin{tabular}{|c|c|c|c|c|}
\hline SL. No & Questions & Yes & No & Don't know \\
\hline 1. & Are you satisfied with the content of lectures? & $76.6 \%$ & $15 \%$ & $8.4 \%$ \\
\hline 2. & $\begin{array}{c}\text { Do you feel that important points have be adequately highlighted } \\
\text { during lectures and practical classes? }\end{array}$ & $93.3 \%$ & $0 \%$ & $6.7 \%$ \\
\hline 3. & $\begin{array}{l}\text { Are you satisfied with the explanations given during lectures and } \\
\text { practical classes? }\end{array}$ & $78.3 \%$ & $10 \%$ & $11.7 \%$ \\
\hline 4. & Are you satisfied with the delivery and pace of the lectures? & $68.3 \%$ & $25 \%$ & $6.7 \%$ \\
\hline 5. & $\begin{array}{l}\text { Are you encouraged to ask questions and give answers during the } \\
\text { classes? }\end{array}$ & $76.6 \%$ & $13.3 \%$ & $10.1 \%$ \\
\hline 6. & Are the number of classes taken in pathology adequate? & $85 \%$ & $8.3 \%$ & $6.7 \%$ \\
\hline 7. & Are duration of each of the classes adequate? & $81.6 \%$ & $11.6 \%$ & $6.8 \%$ \\
\hline
\end{tabular}

Table-3: Teaching tools.

\begin{tabular}{|c|c|c|c|c|c|}
\hline Sl. No & \multicolumn{2}{|c|}{ Questions } & Yes & No & Don't know \\
\hline 1. & \multicolumn{2}{|c|}{$\begin{array}{l}\text { Are the displayed lecture material easy to follow and } \\
\text { satisfactory? }\end{array}$} & $88.3 \%$ & $8.3 \%$ & $3.4 \%$ \\
\hline 2. & \multicolumn{2}{|c|}{$\begin{array}{l}\text { Are the images, flow charts and graphics used during the } \\
\text { lectures relevant to the topic? }\end{array}$} & $91.6 \%$ & $6.6 \%$ & $1.8 \%$ \\
\hline 3. & \multicolumn{5}{|c|}{$\begin{array}{l}\text { Are these following kinds of teaching learning methods useful for learning and understanding } \\
\text { pathology? }\end{array}$} \\
\hline a. & Black board teaching & $78.3 \%$ & $16.6 \%$ & & $5.1 \%$ \\
\hline b. & Powerpoint presentations & $85 \%$ & $10 \%$ & & $5 \%$ \\
\hline c. & $\begin{array}{l}\text { case based discussions and group } \\
\text { discussions }\end{array}$ & $96.6 \%$ & $0 \%$ & & $3.4 \%$ \\
\hline d. & Integrated teaching & $83.3 \%$ & $12.7 \%$ & & $4 \%$ \\
\hline e. & Pathology museum & $61.6 \%$ & $23.3 \%$ & & $15.1 \%$ \\
\hline f. & Seminars and symposium & $68.3 \%$ & $28.3 \%$ & & $3.4 \%$ \\
\hline $\mathrm{g}$ & quizzes & $53.3 \%$ & $40 \%$ & & $6.7 \%$ \\
\hline
\end{tabular}

Table-4: Modes of assessment.

\begin{tabular}{|c|c|c|c|c|}
\hline Sl. No & Questions & Yes & No & Don't know \\
\hline \multicolumn{2}{|c|}{ Are the following modes of assessment helpful in improving knowledge and application skills? } \\
\hline 1. & Written exams & $96.6 \%$ & $3.4 \%$ & $0 \%$ \\
\hline 2. & Viva voce & $88.3 \%$ & $11.7 \%$ & $0 \%$ \\
\hline 3. & Practical exams & $90.6 \%$ & $6.4 \%$ & $3 \%$ \\
\hline
\end{tabular}


Research Article

Regarding the teaching-learning tools employed for pathology classes, majority (85\%) agreed that PowerPoint presentation was very useful in teaching and understanding pathology. Other popular modes were case-based discussions and group discussion $(96.6 \%)$, black board teaching (78.3\%) and integrated teaching (83.3\%). Quizzes, seminars \& symposiums and use of the departmental museum were perceived by the students as least useful in studying and understanding pathology. Most of the students, $88.3 \%$, agreed that the lectures and practical classes highlighted concepts in an easy to follow manner and with good legibility. $91.6 \%$ also agreed that images, flowcharts and graphics that were used during the course of the lectures were relevant to the topic and useful for understanding the topic (Table 3).

Regarding the modes employed for assessment of the students, 96.65 of the students agreed that written exams were a very effective assessment tool. $88.3 \%$ felt viva and $90.6 \%$ felt practical exams were also useful tool in assessing the knowledge of the students, while only $10 \%$ felt viva was not useful in assessment of knowledge and application skills of the students (Table 4).

Among the changes suggested by the students, the point most mentioned was that more practical exams and monthly tests need to be conducted because pathology was perceived as a vast subject. Lack of effective teacher-student communication was also mentioned in $6 \%$ of the feedback forms.

\section{Discussion}

Pathology bridges the gap between basic sciences and clinical medicine, so a proper understanding of pathological processes is vitally important for medical practice [2]. Over the years pathology has developed from an autopsy and macroscopy based discipline to a technically finessed histological and molecular field. Students must understand the importance of pathology as an interdisciplinary field [4].

Teaching is a task that requires enthusiasm and time, and, if done with commitment, is greatly rewarding. If pathology teachers are do a good job of imparting knowledge, then, there is hope that newly qualified doctors will understand the mechanisms of disease, use laboratories properly and be stimulated to become pathologists themselves. If not, there is the danger of producing doctors who cannot explain disease to their patients, who abuse laboratories and who have no interest in pursuing pathology as a career, leading to a slow and possibly irreversible decline in pathology as a medical profession [2].

In teaching, students' wishes regarding the curriculum and the teaching-learning methods employed are of utmost importance, especially in a field like pathology where teaching must be trimmed to assist students in effectively retaining extensive amounts of knowledge [4]. Feedback from students is an integral and important element of teaching as it encourages and enhances knowledge, skills and professional performance of teachers. Although there are various methods of teachers' evaluation, student's feedback is considered as the most effective and reliable method. It is also inexpensive and easy to obtain [5]. In the present study, all the $81(100 \%) 2^{\text {nd }}$ MBBS students responded to the questionnaire. Female students out-numbered the male students in our study in the ratio 6:1. This was similar to the study conducted by Quadri et.al [6].

In our study we found that most students had a positive attitude towards pathology with most agreeing that a sound knowledge of pathology was useful for their clinical practice in future. An integrated mode of teaching pathology along with other clinical specialty subjects was preferred by a majority of students as they felt it helps in better understanding of various disease processes. Similar finding was observed in study carried out by Shah et al and Goyal et al.who mentioned that integrated teaching method could be useful and time saving $[1,7]$. The study by Rafique $\mathrm{N}$ showed integrated teaching is effective to enhance the skill of clinicopathological correlation and help to improve the cognitive and psychomotor domains of the students [8].

Most of the students were satisfied with the content $\&$ quality of lectures, duration and number of lectures, stress laid on important points and explanations given by the faculty while clarifying doubts. This was similar to the study conducted by Quadric et.al [6].

Most of the students agreed that case-based discussion and group discussions, the use of Powerpoint presentation during lectures and integrated teachings are the most effective modes of teaching-learning. This was similar to the studies by Goyal et al[7] and Shah et al[1] who recommended the judicious use of audiovisual aids 
along with the conventional methods, so that the powerpoint presentation should complement the teaching methodology. Quizzes and seminars were not perceived to be effective ways of learning by many students. It was also found that many of our students did not regard pathology museum as an effective teaching tool. This reflected a general trend showing decline in the use of departmental museum by the students probably because of access to pictures of gross specimens related to various diseases via the internet. Many studies reports show that today's medical students generally favor an integrated mode of learning and e-learning is often combined with traditional teaching methods as blended learning format $[9,10,11,12]$.

Assessment is considered the most important driving factor of student learning, as students tend to mainly focus on the material to be assessed. Research shows that in the context of higher education (including medical education), the type of assessment method adopted can influence student learning $[13,14,15]$. In most medical schools, practical exercises are an integral part of pathology courses, and the assessment of these practical exercises is greatly important. In the teaching of medical subjects, it is current practice to use extensively applied objective structured practical examination (OSPE) for the assessment of students $[16,17,18]$. In our study, majority agreed that written exams, viva and practical exams were useful tools of assessment. This was similar the study by Quadri et al [6]. Among the changes recommended, 10\% suggested that practical exams be conducted more frequently and also topic-wise monthly tests be conducted.

Another important point mentioned by $6 \%$ of the students was a lack of student teacher interaction. This could be because of the lack of student mentoring programme by faculty in our institution. This can be addressed by assigning small group of students to one faculty in the department so that the faculty takes on the role of a mentor to that group of students. This will help in answering questions, giving advice, listening to the student's problems and difficulties and stimulating reflection. As a more experienced person, a mentor can contribute to the personal and professional development of a young medical student by providing support and orientation, as a role model, helper, and friend [19].

Mentors can also act as critical references during medical students' journey, thereby fostering their wellbeing, personal and professional growth[19].

\section{Conclusion}

Our study showed that most students had a positive attitude towards pathology as a subject as well as the various teaching learning methods employed by the faculty of our department. Most students felt case based discussions and integrated teaching to be among the most effective ways of gaining knowledge. However, many felt the need for conducting practical exams more frequently as well as monthly topic wise exams. Since many students mentioned a lack of student teacher interaction, student mentoring programmes by the faculty may be useful in this scenario.

Acknowledgement: We thank the $2^{\text {nd }}$ Year MBBS students (2015-2016 regular batch) of MES Medical College, Perinthalmanna, Kerala, India for their cooperation in this feedback study.

Funding: Nil, Conflict of interest: None initiated, Permission from IRB: Yes

\section{References}

1. Shah A, Shethwala N, Parmar B. Perception of undergraduate medical students towards the subject of Pathology at one of the Medical Colleges of Gujarat, India. International Journal of Medical Science and Public Health. 2014;3(7):863.

2. Domizio P. 12 The Changing Role of Pathology in the Undergraduate Curriculum. In: Hall PA, Wright NA, editors. Understanding Disease: A centenary celebration of the Pathological Society. London: Wiley; 2006. p. 137-52.

3. Dick F, Leaven T, Dillman D, Torner R, Finken L. Core morphological concepts of disease for second-year medical students. Hum Pathol. 1998 Sep;29(9):1017-20.

4. Herrmann FE, Lenski M, Steffen J, Kailuweit M, Nikolaus M, Koteeswaran R, et al. A survey study on student preferences regarding pathology teaching in Germany: A call for curricular modernization. BMC Medical Education 2015;15(1):94.

5. Khan S, Husain M. Students' feedback: An effective tool in teachers' evaluation system. International Journal of Applied and Basic Medical Research. 2016;6 (3): 178 .

6. Quadri S, Srujana S, Mahesh S, Bheeshma B. Undergraduate medical students' feedback and 
perceptions on teaching learning methodology in Pathology at Government Medical College. International archives of integrated medicine. 2016; 3 (7) : 28-35.

7. Goyal M, Bansal M, Gupta A, Yadav D. Perceptions and suggestions of 2nd professional MBBS students about their teaching and learning process: An analytical study. National journal of integrated research in medicine. 2010;1(4):20-24.

8. Rafique N. Introducing integrated practical examination for 2nd year MBBS class. 7th GCC Medical Colleges Conference. Dammam, Saudi Arabia: Saudi society of Family and Community medicine; 2009.

9. Woltering V, Herrler A, Spitzer K, Spreckelsen C. Blended learning positively affects students' satisfaction and the role of the tutor in the problem-based learning process: results of a mixed-method evaluation. Adv Health Sci Educ Theory Pract. 2009 Dec;14(5):725-38. doi: 10.1007/s10459-009-9154-6. Epub 2009 Jan 30.

10. Gray K, Tobin J. Introducing an online community into a clinical education setting: a pilot study of student and staff engagement and outcomes using blended learning. BMC Med Educ. 2010 Jan 26;10:6. doi: 10.1186/1472-6920-10-6.

11. Back DA, Haberstroh N, Sostmann K, Schmidmaier G, Putzier M, Perka C, et al. High efficacy and students' satisfaction after voluntary vs mandatory use of an elearning program in traumatology and orthopedics- A follow-up study. Journal of Surgical Education 2014;71(1):353-9.
12. Masie E. Blended learning: The magic is in the mix. In: Rossett A, editor. The ASTD E-Learning Handbook. New York: McGraw-Hill; 2002. p. 58-63.

13. Ben-David FM. Association of Medical Education in Europe guide no. 14: outcome-based education: part 3 - assessment in outcome-based education. Medical Teacher. 1999;21(1):23-25.

14. Amin TT, Kaliyan F, Al-Muhaidib NS. Medical students' assessment preferences at King Faisal University, Saudi Arabia. Advances in Medical Education and Practice. 2011; 2(1): 95-103.

15. Epstein RM. Assessment in medical education. New England Journal of Medicine. 2007;356(1):387-96.

16. Dissanayake AS, Ali BA, Nayar U. The influence of the introduction of objective structures practical examinations in physiology on student performance at King Faisal University Medical School. Medical Teacher. 1990;12(1) :297-304.

17. Rahman N, Ferdousi S, Hoq N, Amin R, Kabir J. Evaluation of objective structured practical examination and traditional practical examination. Mymensingh Medical Journal. 2007;16(1) :7-11.

18. Htwe TT, Sabaridah I, Low GK. Comparative assessment of students' performance and perceptions on objective structured practical models in undergraduate pathology teaching. Singapore Medical Journal. 2014; 55(9):502-505.

19. Bellodi, Patrícia Lacerda. Mentors, students, and the undergraduate medical course: a virtuous circle. Revista Brasileira de Educação Médica, 2011; 35(3), 382-388

\section{How to cite this article?}

Vijayan P, Ponniah A. A survey study based on undergraduate medical students' feedback regarding pathology and the teaching-learning methodologies employed. Trop J Path Micro 2017;3(2):149-154.doi: 10.17511/jopm.2017.i2.14. 